\title{
Coleta e registro de sinais-termos psicológicos para Glossário de Libras
}

\author{
Francielle Cantarelli Martins ${ }^{1}$ \\ Marianne Rossi Stumpf ${ }^{2}$
}

\section{Resumo}

Este trabalho tem seu foco de estudo em terminologias específicas da área de Psicologia em Língua Brasileira de Sinais (Libras) e como elas são sinalizadas. O objetivo desta pesquisa preliminar é coletar e registrar os sinais-termos de Libras existentes na área de Psicologia a partir de três psicólogos surdos de diferentes regiões do país. O trabalho se justifica pela falta de registro de sinais-termos variantes - variação linguística - da área de Psicologia, o que interfere na negociação de sentidos e dos conceitos pela comunidade surda acadêmica. Como parte do método, a pesquisa coleta os sinais-termos de autores da Psicologia utilizados por profissionais da área. Foram encontrados 23 autores e 28 sinais-termos. Os sinais-termos da área de Psicologia que este trabalho coletou e registrou foram postados no glossário de Letras, para que comunidade surda acadêmica possa acessar e conhecer os sinais-termos com facilidade.

Palavras-chave: sinais-termos, libras, psicologia, terminologia

${ }_{1}$ Doutoranda no Programa Pós-Graduação em Linguística da Universidade Federal de Santa Catarina, Florianópolis/Santa Catarina. E-mail: franciellecantarellim@gmail.com

2 Docente e orientadora no Programa Pós-Graduação em Linguística da Universidade Federal de Santa Catarina, Florianópolis/Santa Catarina. E-mail: stumpfmarianne@ gmail.com 


\section{Abstract}

This work focus on studying psychology area of terminology in Brazilian Sign Language - Libras, studying specific terminologies and how they are sign. The aim of this article is to collect and record the sings-terms that exist in psychology area. This preliminary research shows the authors signterms used by three deaf psychologists from different regions. This work is justified by the lack of record of the terms-signs variants - linguistic variation - of psychology area, which interferes in the negotiation of meanings and concepts by academic deaf community. As part of the method, the survey collects the signal-terms of psychological authors used by professionals. We have found 23 authors of the area and 28 signs-terms. Also, as part of the methodology, it will be collected more concepts of the area and then the signs will be posted in the Letras Libras course glossary of so the academic deaf community can access and know the signs-terms easily.

Keywords: sign-terms, libras, psychology, terminology

\section{Introdução}

A produção de neologismos terminológicos em Libras vem se desenvolvendo na Universidade Federal de Santa Catarina - UFSC - desde 2006, ano que iniciou o projeto Glossário Letras-Libras ${ }^{3}$ (atualmente Glossário de Libras), como fruto de uma necessidade da graduação em Letras-Libras a distância. Como a maioria dos acadêmicos é surda, o curso tem tradução dos textos-bases das disciplinas para Libras através de uma equipe de tradutores surdos que trabalham nessa função, disponibilizando on-line materiais em Libras aos acadêmicos (pelo endereço www.libras. ufsc.br), a fim de que eles possam acessar e aprender os conteúdos através da Libras - sua primeira língua.

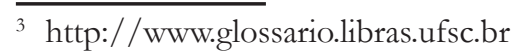


Quando a equipe começou a trabalhar com os conteúdos acadêmicos, percebeu que muitos termos técnicos não tinham sinais, ou seja, existiam na Língua Portuguesa, mas em Libras não eram encontrados os sinais-termos ${ }^{4}$ correspondentes. Iniciou-se, então, uma discussão sobre os termos técnicos das áreas específicas para o curso de Letras-Libras, a fim de convencionar os sinais, respondendo às necessidades comunicativas dos surdos, resultando no projeto Glossário Letras-Libras em 2006. O projeto tem o objetivo de disponibilizar os sinais-termos para tradutores/intérpretes, docentes, discentes e profissionais da área de Letras-Libras. A equipe começou a coletar os sinais-termos para o banco de dados da área de Letras-Libras e, além deste, hoje já estão finalizados os glossários de Arquitetura e Cinema. Atualmente estão em construção os glossários das áreas de Psicologia e Informática.

A divulgação dos sinais-termos do glossário por acadêmicos do curso em outros espaços demonstrou a necessidade de ampliação e disponibilização desse banco de dados para a comunidade surda acadêmica.

Tal ferramenta, além de contribuir para a tarefa dos tradutores do curso Letras-Libras, tem como objetivo oportunizar a consulta de outros tradutores profissionais e em formação, buscando favorecer a tradução de textos especializados de forma sistematizada e possibilizando a consolidação de um campo relevante dos Estudos da Tradução em Libras (STUMPF, OLIVEIRA e MIRANDA, 2014, p. 153).

Os autores argumentam sobre essa ferramenta que contribui com intérpretes-tradutores e profissionais da área de Libras, contribuindo para melhor compreensão pelos discentes surdos.

${ }_{4}$ Para saber melhor a expressão sinal-termo, Faulstich (2014) explica: "Sinal-termo. 1) Termo da Língua de Sinais Brasileira que representa conceitos com características de linguagem especializada, próprias de classe de objetos, de relações ou de entidades; 2) Termo criado para, na Língua de Sinais Brasileira, denotar conceitos contidos nas palavras simples, compostas, símbolos ou fórmulas, usados nas áreas especializadas do conhecimento e do saber; 3) Termo adaptado do português para representar conceitos por meio de palavras simples, compostas, símbolos ou fórmulas, usados nas áreas especializadas do conhecimento da Língua de Sinais Brasileira". 
Quando surgiu a proposta do desenvolvimento do glossário para a área da Psicologia, a UFSC não tinha nenhum discente surdo matriculado no curso. Porém, existem discentes surdos nessa área em outras universidades, e ainda há psicólogos surdos e ouvintes que atendem pacientes surdos, além de docentes, tradutores/intérpretes e outros profissionais que trabalham na área da Psicologia. Por isso, é importante essa discussão, para que todos possam acessar e conhecer os sinais-termos.

Durante o levantamento de referenciais bibliográficos, foram encontradas duas pesquisas lexicográficas com alguns sinais-termos da área da Psicologia, que são: Lexicografia da Língua de Sinais do Rio Grande do Sul (MARTINS, 2012) e Dicionário Enciclopédico Trilíngue da Língua Brasileira de Sinais (CAPOVILLA, RAPHAEL e MAURÍCIO, 2012). Na primeira pesquisa citada (MARTINS, 2012), a autora concluiu a dissertação de mestrado da Universidade de São Paulo sobre Lexicografia da Língua de Sinais Brasileira do Rio Grande do Sul, quando coletou vários sinais-termos utilizados pelas pessoas surdas do Estado. Porém, apenas uma amostra dos sinais coletados está publicada na dissertação. Foram divididas as seguintes categorias semânticas:

Tabela 1: Categorias Semânticas

\begin{tabular}{|l|c|}
\hline \multicolumn{1}{|c|}{ Áreas } & Sinais-termos \\
\hline Psicologia & 16 \\
\hline Perspectiva histórica da Psicologia & 7 \\
\hline Áreas da Psicologia & 24 \\
\hline Áreas relacionadas à Psicologia & 12 \\
\hline Etapas da alfabetização & 2 \\
\hline Psicoterapias & 7 \\
\hline Conceitos psicanalíticos & 8 \\
\hline Princípios da terapia cognitivo comportamental & 8 \\
\hline Abusos e violências & 4 \\
\hline Técnicas de modificacão comportamental & 4 \\
\hline Instrumentos de avaliacão & 4 \\
\hline Testes projetivos & 1 \\
\hline Testes psicométricos & 2 \\
\hline Sintomas psicológicos e psiquiátricos & 7 \\
\hline Transtornos psicológicos e psiquiátricos & 23 \\
\hline Transtornos de linguagem & 10 \\
\hline Teóricos & 11 \\
\hline Total & 150 \\
\hline
\end{tabular}

Fonte: MARTINS, 2012 
Alguns desses sinais-termos já foram publicados no Novo DeitLibras: Dicionário Enciclopédico Ilustrado Trilíngue (2012), que tem vários sinais-termos de Libras, coletando variantes regionais brasileiras. Segundo a autora, os demais sinais resultantes da pesquisa serão publicados nas próximas edições da obra. O dicionário conta com alguns sinais da Psicologia, porém em número insuficiente para o aprofundamento teórico e a construção de sentidos na área. É importante saber que os dicionários gerais, diferentemente da pesquisa aqui proposta, não possuem foco terminológico.

A presente pesquisa se justifica pela falta de terminologias científicas em Libras, o que interfere na negociação de sentidos e dos conceitos por tradutores/intérpretes, docentes, discentes e profissionais. A difusão de sinais-termos da área de Letras-Libras é muito recente e, embora quase todos os termos já tenham sinais, ainda faltam alguns em áreas específicas, como a da Psicologia.

\section{Contextualização}

As pesquisas de Línguas de Sinais têm sua história. Em 1960, nos Estados Unidos, o linguista William Stokoe descreveu os parâmetros fonológicos da Língua de Sinais Americana (ASL), isto é, configuração de mão, movimento e ponto de articulação, e assim comprovou que a ASL tem estrutura e demais aspectos necessários para ser considerada como uma língua. Após essa pesquisa, surgiram pesquisas em outros países que comprovam a importância das línguas de sinais, uma vez que sujeitos surdos se comunicam através das línguas de sinais, como os ouvintes através de línguas orais. No Brasil, através das pesquisas de Ferreira-Brito (1995), Quadros (1997) e Quadros e Karnopp (2004), comprovou-se que a Libras também tem status linguístico.

As pesquisas surgiram no Brasil na década de 1980, com a linguista Lucinda Ferreira Brito (1984, 1990, 1993, 1995), quando esta apresentou 
que no Brasil há duas línguas de sinais brasileiras, a língua de sinais dos centros urbanos brasileiros (atualmente referida como Libras) e a língua de sinais Urubu-Kaapor (pertencente à família Tupi-Guarani e usada na comunidade indígena Urubu-Kaapor, do interior do Maranhão). A pesquisadora analisou as diferenças e similaridades das duas línguas: espaço, intensificador e quantificador, dentre outras. Já na década de 1990, ampliaram-se as produções acadêmicas com outros linguistas, como Felipe (1998), Karnopp (1994, 1999) e Quadros (1997, 1999). Como as pesquisas científicas fundamentais das línguas de sinais são recentes e fundamentais, ainda não há muitas investigações sobre terminologia como a que estamos construindo, faltam estudos sobre terminologia de áreas específicas.

\section{Terminologias}

Terminologia é o estudo e uso dos termos, descrevendo-os nos contextos específicos. É uma área cientifica que estuda os rótulos e conceitos de diversos campos, documentando e divulgando o uso correto dos termos em cada área.

Maria Tereza Cabré (1995) explica a necessidade das pesquisas em torno das terminologias, visto a importância de seus fundamentos, enfoques, aplicações práticas, para polissemia do termo, usados tanto para disciplina, quanto para prática e produto, facilitando o uso para os especialistas da área. Assim como Cabré, Juan Carlos Sager (1998) afirma que, como teoria, a terminologia é um conjunto de argumentos e conclusões necessários para explicar o relacionamento entre conceitos e termos especializados. Ele continua dizendo que a terminologia é prática para cada área, é um conjunto de métodos e atividades voltado para coleta, descrição, processamento e apresentação de termos. Como produto, é um conjunto de termos, ou vocabulário, de uma determinada especialidade. 
Como visto, as terminologias focam os conceitos específicos de cada área, os quais geralmente são utilizados apenas por especialistas que atuam nela. Então, esse trabalho se baseia nas terminologias, nos sinaistermos específicos da área da Psicologia, no seu registo, a fim de que os profissionais, mesmo que em regiões diferentes, possam utilizá-los na comunicação com sujeitos surdos.

Tradutores/intérpretes, pesquisadores e outros profissionais da área poderão utilizar os resultados da pesquisa como dicionários e glossários técnicos. Krieger (1998) argumenta que não apenas especialistas da área utilizam a terminologia, mas também discentes e profissionais, dentre outros.

O interesse não se restringe mais aos especialistas que, como usuários diretos, sempre compreenderam a necessidade de dominar as terminologias de suas áreas de competência. Entre os usuários indiretos da terminologia, destacam-se os tradutores, intérpretes, documentalistas, os redatores técnicos, lexicógrafos e terminógrafos, estudantes universitários, entre outras categorias de profissionais que se envolvem com a linguagem (KRIEGER, 1998, p. 2).

Acadêmicos surdos que estudam em áreas da saúde e seus tradutores/intérpretes, bem como pessoas que se envolvem na área de Psicologia para surdos, e ainda docentes de Libras que lecionam no curso de Psicologia, podem usar terminologia.

\section{Terminologias em Libras}

Há pesquisas semelhantes sobre terminologia em Libras de área específica, como Arquitetura, Biologia e Química. A pesquisadora Margot Latt Marinho, em 2007, publicou O ensino da biologia: o intérprete e a geração 
de sinais. A autora observou que a carência de sinais-termos de Biologia fazia com que a interpretação na sala de aula fosse prejudicada. O estudo traz análises das dificuldades e limitações vividas por discentes surdos, intérpretes/tradutores educacionais e docentes no ensino da Biologia, no que tange à terminologia científica. A pesquisadora observou um grupo de discentes surdos em uma escola pública e percebeu as dificuldades no entendimento, mesmo com a presença do tradutor/intérprete na sala de aula, com a adoção de estratégias interacionais e com a utilização de material visual, tornando-se necessária a criação de sinais em Libras para os termos da Biologia.

A primeira pesquisa sobre lexicografia e terminologia em Libras foi a tese de doutorado de Sandra Patrícia de Faria do Nascimento, na Universidade de Brasília, em 2009. Representações lexicais da língua de sinais brasileira: uma proposta lexicográfica teve como foco a combinação de entidades morfológicas que compõem o léxicon, que envolvem os parâmetros, os movimentos, as configurações de mão, os pontos de articulação e os parâmetros complementares. Dentre os parâmetros complementares, destacam-se: orientação da palma da mão e expressões não manuais, classificadores, morfemas-base, unidades lexicais emprestadas, elementos prototípicos, metonímias, metafóricos, ícones linguísticos e os empréstimos de letras da língua portuguesa. O objetivo foi compreender os processos de denominação de categorias e de construção dos classificadores da Libras para organizar entradas nos repertórios lexicográficos da Libras.

A pesquisa também apresentou a proposta lexicográfica com organização de semasiológica e onomasiológica, apresentados para contextos bilíngues (Libras e Língua Portuguesa). A pesquisadora se propôs a criar subsídios para elaborar outros dicionários e materiais didáticos, pois percebeu que há surdos brasileiros na graduação que precisam receber acesso ao conhecimento científico, principalmente na expansão terminológica de Libras, para melhor compreensão. Sua pesquisa 
(repertórios terminológicos) pode ser vista e acessada pelos surdos para obter informações cientificas e técnicas.

Os pesquisadores Sinval Fernandes de Sousa e Hélder Eterno da Silveira (2011) realizaram o estudo de terminologias da área de Química da Universidade Federal de Uberlândia, com discentes surdos, docentes e tradutores/intérpretes de Libras, buscando compreender como esses profissionais ensinam conceitos químicos e como ocorre a apropriação e a utilização de sinais de termos químicos em Libras para aprendizagem de discentes surdos. Eles observaram que tanto os docentes quanto os tradutores/intérpretes demonstravam dificuldades em abordar os conteúdos de Química para discentes surdos por falta de sinais-termos técnicos da área. Os pesquisadores analisaram como é o processo de apropriação e utilização de alguns sinais por discentes surdos em aulas de Química e suas relações com os conceitos químicos, e concluíram que a falta de material de apoio didático-pedagógico em Química voltado aos surdos foi um dos fatores apontado pelas intérpretes que dificulta o ensino-aprendizagem desse conteúdo, principalmente em relação aos conceitos abstratos e à simbologia utilizada nessa ciência (SOUZA E SILVEIRA, 2011). Na aula de Química, tradutores/intérpretes criaram os sinais-termos não oficiais com discentes surdos para não perderem os conteúdos, mas eles não foram publicados nem divulgados. Os pesquisadores concluíram que é importante discutir com profissionais da área - docentes, tradutores/intérpretes, pesquisadores - para que seja possível melhorar a terminologia de Química.

Vera Lúcia Souza Lima (2014) concluiu a tese da Universidade Federal de Minas Gerais, cujo título é Lingua de Sinais: Proposta terminológica para a área de desenho arquitetônico. Ela pesquisou sobre o desenvolvimento de uma metodologia que proporcionou a elaboração de um glossário bilíngue ilustrado e bimodal, isto é, que contempla a Língua Portuguesa e a Língua de Sinais, fundamentado em um corpus de termos da área do projeto arquitetônico. A autora tinha projetos de pesquisa nos quais trabalhava, em 
conjunto com sua equipe, com um glossário para que os acadêmicos surdos acessassem sinais-termos técnicos da área da Arquitetura, principalmente para cursos técnicos ou superiores dessa área.

A pesquisadora Janine Soares de Oliveira concluiu sua tese de doutorado, intitulada Análise descritiva da estrutura de unidades terminológicas do glossário Letras-Libras, no ano de 2015. A autora analisou a estrutura das unidades terminológicas do glossário Letra-Libras em uma pesquisa descritiva no banco de dados, com os sinais postados entre 2008 e 2010 . O objetivo foi identificar e descrever os elementos querológico-morfológicos de unidades terminológicas em Libras. O resultado da pesquisa oportunizou a validação e contribuiu uma aplicação direta e funcional no sistema do Glossário Letras-Libras no sentido de permitir gerar uma sistemática de acesso bidirecional a esse glossário no futuro.

$\mathrm{Na}$ última pesquisa que encontramos, o pesquisador Brenno Barros Douettes concluiu a dissertação de mestrado da Universidade Federal de Santa Catarina, no ano 2015, com o título A tradução na criação de sinais-termos religiosos em Libras e uma proposta para organiz̧ação de glossário terminológico semibilíngue. A pesquisa discutiu sobre terminologia religiosa construída em Libras em três manuais religiosos: 1. Religião católica - Linguagem das Mãos (OATES, 1969); 2. Religião Batista - Clamor do Silêncio (JMN, 1991), e; 3. Testemunhas de Jeová - Linguagem de Sinais (TJ, 1992). O autor construiu uma tabela que apresenta verbetes encontrados em cada obra, com sinais similares entre os três, entre dois ou em apenas um dos manuais. O estudo foi finalizado com uma proposta para organização de um glossário semibilíngue com sinaistermos religiosos e apresentou o modelo de glossário de sinais bíblicos (93 sinais), que vêm acompanhados de seus respectivos conceitos e exemplos. Todos estão listados no menu do DVD e possuem versão para web. 


\section{Terminologia de Psicologia em Libras}

Os pesquisadores do Glossário Letras-Libras trabalharam com os sinais-termos técnicos de 2006 a 2010, quando, então, a equipe se tornou mais independente, abrindo espaço para que sujeitos além dos tradutores / intérpretes participassem, como docentes, discentes. As discussões sobre neologismos em Libras foram ampliadas, bem como a criação de mais sinais-termos técnicos. A autora Janine Soares de Oliveira escreveu sobre como a equipe começou a ampliar sua pesquisa:

Neste ano de 2010, a equipe do Glossário deixou de fazer parte do conjunto de tarefas da equipe de tradução, embora ainda conte com a participação de todos os membros da primeira equipe. Isto é, a equipe está mais independente com espaço e momento próprios para discussões e pesquisas, e assessoria direta de professores convidados. A discussão permanente entre tradutores é indispensável e realizada sistematicamente em encontros semanais, tendo como objetivo a criação de neologismos que ampliam constantemente o léxico instrumental de Libras. Nas discussões do grupo, cada tradutor apresenta resultados de pesquisa realizada com representantes de comunidades surdas de todo o Brasil (OLIVEIRA, 2010, p. 3).

A equipe do glossário ampliou seu alcance para várias áreas específicas e mais membros da comunidade surda. No mesmo sentido, optamos por trabalhar com a área da Psicologia porque percebemos que muitos profissionais e discentes desta se queixam das dificuldades de sinalizar e/ou de interpretar os conteúdos de Psicologia, pelo fato de que muitos termos técnicos não têm sinais. Nas experiências de tradutores/intérpretes e discentes surdos do curso superior de Psicologia, muitos soletram ${ }^{5}$ os termos, pois não os conhecem e sabem que ainda não foram criados sinais oficiais. Além disso, os termos de

${ }^{5}$ Soletração é usada para expressar substantivos próprios e também palavras que não possuem sinal conhecido ou, ainda, palavras da língua portuguesa. 
Psicologia podem ser utilizados em outras áreas, como Educação, Linguística e Medicina.

Assim, começamos a trabalhar com a terminologia com o Glossário Letras-Libras, porque esse projeto foi ampliado para várias áreas específicas, como Cinema e Arquitetura. Buscamos psicólogos surdos para saber se eles conhecem alguns sinais específicos e descobrimos que a maioria deles não utiliza os termos específicos, porém alguns criam os sinais-termos, só que não registram nem divulgam para a comunidade acadêmica. Esse é um dos desafios para o glossário: registrar os sinais técnicos da área da Psicologia.

\section{Método}

Apresentamos agora quais as propostas e estratégias para registrar os sinais-termos psicológicos em Libras nesta pesquisa. Já mencionamos que é importante registrar os sinais-termos das áreas específicas para que profissionais e discentes possam consultá-los. Existem poucas áreas nas quais os dicionários e glossários especializados em Libras foram explorados. Neste trabalho, focalizamos os sinais-termos da área da Psicologia.

O objetivo geral é investigar e registrar os sinais-termos de Libras existentes na área da Psicologia, como também disponibilizar um banco de sinais terminológicos que auxilie os tradutores/intérpretes, docentes e discentes.

Dentre os objetivos específicos, destacam-se: 1. Listar os termos mais usados da área da Psicologia; 2. Encontrar os psicólogos surdos que utilizam os sinais-termos científicos em Libras; 3 . Registrar os sinaistermos existentes nos fichamentos; 4. Validar os sinais-termos com a equipe de glossário de Libras; 5. Publicar os sinais-termos validados na página do Glossário de Letras Libras. 
Cada trabalho terminológico (dicionário, vocabulário, glossário) precisa de uma metodologia adaptada às particularidades da área em estudo. Isso não significa que cada trabalho exija uma metodologia única, pois é possível adaptar metodologias já circunscritas e traçadas às necessidades do trabalho a ser feito (BRAGA, 2010).

Então, este trabalho optou por utilizar o Glossário de Letras Libras, pois este é um sistema que tem arquitetura de glossário que apresenta Libras, consulta em configuração de mão, Português, Inglês e ordem alfabética. Além das variadas formas de busca, ainda disponibiliza a descrição do sinal e um exemplo. Salientamos que o foco não são os sinais que possuem sinonímias, mas sinais convencionados cientificamente.

\section{Etapas}

A primeira etapa para a coleta dos sinais-termos específicos foi a realização de um fórum on-line em uma rede social, isto é, um grupo fechado para psicólogos surdos sinalizantes. Como foi mencionado anteriormente, o Brasil carece de profissionais da área da Psicologia que se dediquem a estudar e cuidar da saúde dos sujeitos surdos. Assim, para que se pudesse alcançar o maior número possível de profissionais, a pesquisadora optou pela rede social, por esta ter grande abrangência e assiduidade entre os participantes. Foi necessária a busca pelos psicólogos surdos do Brasil, mas, após o início, quando ficaram sabendo da pesquisa, alguns nos procuraram com interesse em participar da discussão, coleta e garimpo dos sinais-termos. Reunimos 14 psicólogos e solicitamos que produzissem vídeos de sinais-termos da Psicologia e áreas afins que conhecessem. Além disso, solicitamos que outros vídeos fossem postados livremente, como suas pesquisas, dúvidas teóricas, ideias e artigos científicos, bem como divulgação de seminários, congressos, cursos e palestras. A exigência era que tudo tivesse relação próxima com a área da Psicologia. 
O grupo promoveu discussões sobre as temáticas surdez e Psicologia, e questões sobre a melhor linha da Psicologia para os sujeitos surdos, a validade ou não do atendimento virtual, bem como a presença de intérprete no setting terapêutico foram levantadas e vastamente discutidas.

$\mathrm{Na}$ segunda etapa, percebemos que não eram todos que sabiam sinais-termos, porque não havia glossário em Libras da área de Psicologia, então a maioria deles utilizava soletração nas aulas e trabalhos. Decidimos refletir sobre critérios que poderiam ser utilizados na pesquisa, mas não encontramos nenhum material bibliográfico que pudesse servir de auxílio nessa etapa. Então, construímos os critérios básicos: buscamos psicólogos surdos que têm experiências como terapeutas e que atendem pacientes surdos, cada um morando em estados diferentes (no Sul e no Sudeste); se trabalham ou trabalhavam como terapeutas; se têm experiências e sinaistermos da área especialidade e ainda o tempo de formação. Com base nos critérios, encontramos três psicólogos surdos:

Tabela 2: Psicólogos Surdos participantes da pesquisa

\begin{tabular}{|c|c|c|}
\hline Participante & Tempo de formação & Região \\
\hline 1 Participante & 32 anos de formação & Sul \\
\hline 2 Participante & 12 anos de formação & Sudeste \\
\hline 3 Participante & 5 anos de formação & Sudeste \\
\hline
\end{tabular}

Fonte: A autora

$\mathrm{Na}$ terceira etapa, coletamos os termos em português que são mais utilizados em aulas, palestras, reuniões e situações do cotidiano, totalizando 100 termos da área da Psicologia. Questionamos quais sinais utilizavam para cada termo e os participantes enviaram vídeos contendo os sinais conhecidos. Salientamos que eles assinaram o Termo de Consentimento Livre e Esclarecido. O envio dos sinais foi em vídeo, pois os participantes são nativos em Libras, que é uma língua e visual-espacial. 
$\mathrm{Na}$ quarta etapa, coletamos os vídeos nos quais os participantes enviaram os sinais-termos e levamos para a equipe do glossário de Libras, a fim de apresentar os sinais e as definições propostas para nosso entendimento. Nesses momentos, imaginamos como os discentes surdos compreenderiam os sinais. Após a explicação, ocorre um processo de validação pela equipe, que tem pesquisadores e tradutores/intérpretes que trabalham nas áreas especificas de registro terminológico. A pesquisadora tem formação em Psicologia e conhecimento sobre estudos linguísticos em Libras, possibilitando a análise e validação dos novos sinais-termos para, em seguida, a equipe também avaliar e validar. Depois da validação, tradutores/intérpretes sinalizam os novos sinais-termos e a gravação é postada no sistema Glossário de Libras.

\section{Análise e discussão}

Recebemos 181 vídeos dos participantes, exceto os de alguns sinaistermos dos quais eles não tinham conhecimento. É interessante perceber as variações existentes entre os participantes que residem em regiões diferentes.

A construção dos sinais-termos está em andamento, porém, até o momento, podemos perceber três categorias: autores, termos específicos e termos gerais da área de Psicologia. Nesta pesquisa preliminar, apresentamos os sinais dos autores e também analisamos os sinais-termos.

$\mathrm{Na}$ categoria "autores", catalogamos 23 sinais, sendo eles: Jean Piaget, Kurt Lewin, Carl Rogers, Carl Gustav Jung, Kurt Koffka, Erik Homburger Erikson, Charles Robert, Darwin, Melanie Klein, Jacob Levy Moreno, Burrhus Frederic Skinner, Karl Abraham, Anna Freud, Sigmund Freud, Jacques-Marie Emile Lacan, Lev Vygotsky e Henri Paul H. Wallon. Para cada autor, localizamos de um a três sinais convencionados. Após o envio dos vídeos, a pesquisadora reproduziu os sinais em foto para análise. Foram escolhidos, para esse momento, quatro autores: 
Tabela 3: Sinais para Sigmund Freud

\begin{tabular}{|c|c|c|}
\hline \multicolumn{3}{|c|}{ Sigmund Freud } \\
\hline Participante 1 & Participante 2 & Participante 3 \\
\hline
\end{tabular}

Fonte: A autora

Tabela 4: Sinais para Jean Piaget

\begin{tabular}{|l|c|c|}
\hline \multicolumn{3}{|c|}{ Jean William Fritz Piaget } \\
\hline Participante 1 & Participante 2 & Participante 3 \\
\hline
\end{tabular}

Fonte: A autora

Tabela 5: Sinais para Carl Jung

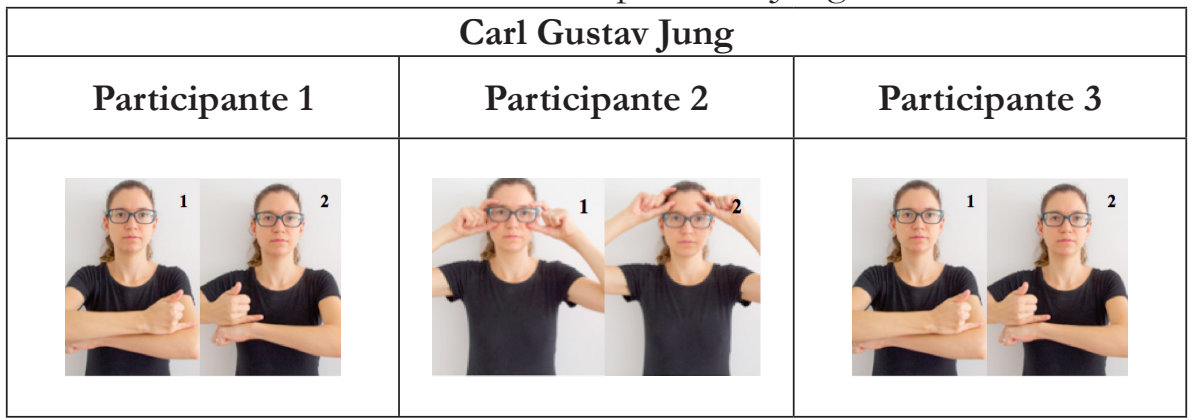

Fonte: A autora 
Tabela 6: Sinais para autor Lev Vygotsky

\begin{tabular}{|l|c|c|}
\hline \multicolumn{3}{|c|}{ Lev Semenovitch Vygotsky } \\
\hline Participante 1 & Participante 2 & Participante 3 \\
\hline
\end{tabular}

Fonte: A autora

\section{Discussão dos resultados}

É interessante observar que participantes que residem em regiões variadas do país utilizam alguns sinais diferentes. Na categoria de autores, recebemos 23 vídeos, analisamos quatro para esta pesquisa e criamos a tabela para facilitar a visualização:

Tabela 7: Variação dos sinais dos autores

\begin{tabular}{|l|c|}
\hline \multicolumn{1}{|c|}{ Autores } & Quantos sinais variantes \\
\hline Sigmund Freud & 3 \\
\hline Sir Jean William Fritz Piaget & 2 \\
\hline Carl Gustav Jung & 2 \\
\hline Lev Semenovitch Vygotsky & 2 \\
\hline
\end{tabular}

Fonte: A autora

Percebemos que há até 3 sinais variantes e, a partir disso, pensamos em dois motivos pelos quais isso acontece, sendo o primeiro a variação linguística, porque participantes que moram em diferentes estados utilizam sinais distintos.

Como em qualquer língua, o português tem variação linguística, como, por exemplo, aipim, macaxeira e mandioca, entre outros. Como língua, a Libras também possui essa variação, então, é preciso ter 
atenção a ela em cada unidade federativa do Brasil. A autora Lodenir Becker Karnopp escreveu sobre variação linguística em suas pesquisas, argumentando que todas as comunidades têm língua e sempre há diversidade e variação. Ela diz:

Ao estudarmos as línguas de sinais, estamos tratando também das relações entre linguagem e sociedade. A linguística, ao estudar qualquer comunidade que usa uma língua, constata, de imediato, a existência de diversidade ou de variação, ou seja, a comunidade linguística (no caso aqui investigado, a comunidade de surdos) se caracteriza pelo emprego de diferentes modos de usar a língua de sinais. A essas diferentes maneiras de fazer sinais, utilizase a denominação de "variedade linguística" (KARNOPP, s/d, p. 6-7).

O segundo motivo da variação por região é que as pesquisas de língua de sinais começaram há décadas, e, assim como os movimentos e as lutas dos sujeitos surdos, foram legitimadas como língua e comunicação dessas pessoas. Porém, foi apenas há vinte anos, em 1993, que os movimentos se intensificaram para oficializar a Libras, vitória que a comunidade surda conquistou em 2002, através da Lei no 10.436, de 24 abril de 2002. Depois dessa batalha, as pesquisas e movimentos surdos ampliaram-se consideravelmente, sempre surgindo novas pesquisas na área. Naquela época, não havia mídias como internet (vídeos) e televisão com intérpretes de Libras. Atualmente, ainda não há muitos programas de televisão que possuem intérpretes de Libras - provavelmente por isso muitos sujeitos não tenham como acessar mídias com intérpretes e não conheçam os sinais-termos da área específica. Um exemplo comum é um programa de televisão em que jornalistas apresentam uma reportagem sobre saúde do Brasil, a qual pessoas podem escutar e, a partir dela, conhecer termos. Mas, se esse programa não tem intérprete, então como surdos podem conhecer os sinais-termos? 
Os sinais-termos ainda estão em processo de consolidação, por isso continuamos com o objetivo de desenvolvê-los e disponibilizá-los aos poucos para a comunidade surda acadêmica.

Contudo, com muitas discussões na equipe e com o curso de Letras-Libras, a comunidade surda percebeu que é importante criar o neologismo, porque a Libras é uma língua viva, assim como outras línguas, e a comunidade surda sempre utiliza os sinais-termos. A autora Janine Oliveira esclarece sobre a criação de neologismo:

Inicialmente havia resistência por parte dos tradutores para oferecer sugestões de neologismos. Com o aprofundamento das discussões einvestigações consolidou-se o entendimento de que as línguas estão em constante renovação e a criação de neologismos não é um fenômeno exclusivo da Libras. Além disso, assim como nas línguas orais, uma pessoa ou grupo não pode determinar o que deve ou não fazer parte do léxico da língua, no máximo pode-se sugerir, pois será sempre a comunidade de falantes da língua que decidirá se o neologismo proposto será incorporado ao léxico ou será apenas hapax legomenon (OLIVEIRA, 2010, p. 6).

É importante coletar os sinais-termos e divulgá-los para a comunidade surda. Nós entendemos que é importante coletar os sinaistermos da área de Psicologia e divulgar esses sinais na página de Glossário de Libras para que profissionais, tradutores/intérpretes, pesquisadores e acadêmicos da área possam acessar e conhecer os sinais corretos. Além disso, o glossário contribui com a ampliação do sinalário ${ }^{6}$ de Libras:

Conscientizar estudantes surdos, de cursos de graduação, a respeito dos processos de construção terminológica permitirá o enriquecimento ainda mais acelerado da LSB, e a rápida sistematização e divulgação dos neologismos terminológicos acarretará o acesso e o domínio mais rápido, também dos intérpretes para

${ }^{6}$ Sinalário: conjunto de expressões que compõe o léxico de uma determinada língua de sinais (STUMPF, 2005, p. 36). 
adequarem sua tradução ao contexto emergente (FARIANASCIMENTO, 2009, p. 55).

O Glossário é uma obra que auxilia a terminologia para a comunidade surda acadêmica. Oliveira (2010) explica que o Glossário de Libras, como obra de referência em terminologia, contribui para a defesa e a valorização da Língua de Sinais Brasileira, bem como dos intérpretes / tradutores dessa língua.

\section{Considerações finais}

Concluímos que é muito importante discutir sobre novos sinaistermos para a comunidade surda acadêmica, principalmente para a área específica de Psicologia, pois há psicólogos sinalizadores, tradutores/ intérpretes e profissionais que trabalham nessa área e não têm acesso aos dicionários e glossários de especialidades em Libras, por isso este trabalho focaliza sinais-termos para divulgar no sistema de glossário de Libras.

Ainda como parte da metodologia, coletaremos mais conceitos da área e postaremos os sinais-termos no glossário de Libras. A pesquisa está em andamento e pretende coletar sinais que tornarão possível publicar um dicionário com as terminologias da área. Isso apoiará a divulgação dos sinais, além de contribuir para o acesso e facilidade da comunicação das pessoas que precisam utilizar a Libras no contato com os profissionais da Psicologia. No mesmo sentido, facilitará a comunicação dos profissionais que precisam se comunicar com os surdos.

O conhecimento construído pela equipe de Glossário constitui-se em ferramenta de consulta que contribui para instrumentalização dos tradutores/intérpretes, para a melhor qualidade das aulas de graduação e pós-graduação, para pesquisas na área de língua de sinais, uso da comunidade surda, congressos etc. (OLIVEIRA, 2010, p. 5). 
$\mathrm{Na}$ época, havia dificuldade de divulgação e consolidação de neologismos, mas hoje temos tecnologia acessível para a comunidade surda, através da qual pessoas sinalizantes podem acessar e compartilhar vídeos, divulgar sinais-termos.

Atualmente, com a tecnologia acessível às pessoas surdas, especialmente no que se refere à produção e compartilhamento de vídeos via internet, é possível divulgar e registrar uma quantidade realmente significativa de neologismos a cada dia. Com o acesso das pessoas surdas às universidades este fenômeno fica ainda mais evidente e, assim como nas línguas orais, é importante registrar as transformações da Libras (OLIVEIRA, 2010, p. 6).

Finalmente, esperamos que o Glossário de Libras contribua para divulgação dos sinais-termos específicos, principalmente para área de terminologia da Libras. Os sinais-termos ainda não foram postados no sistema, mas pretendemos postar assim que concluirmos a pesquisa.

\section{Referências}

BRAGA, R. C. G. As questões metodológicas em terminologia: o caso do vocabulário sistemático de monitoramento da qualidade da água do submédio do rio São Francisco. In: ISQUERDO, A. N.; FINATTO, M. J. B. (ORGs.). As ciências do léxico: lexicologia, lexicografia, terminologia. Vol. IV. Porto Alegre: Editora da UFRGS, 2010.

CAPOVILLA, F. C.; RAPHAEL, W. D., MAURICIO, A. C. Novo DeitLibras: Dicionário Enciclopédico Ilustrado Trilíngue da Língua de Sinais Brasileira (Libras). São Paulo: Editora de Universidade de São Paulo, 2012. 
DOUETTES, B. B. A tradução na criação de sinais-termos religiosos em libras e uma proposta para organização de glossário terminológico semibilíngue. (Dissertação de mestrado) - Programa de Pós-Graduação em Estudos da Tradução, Universidade Federal de Santa Catarina. Florianópolis, 2015.

FARIA-NASCIMENTO, S. P. Representações lexicais da língua de Sinais Brasileira: uma proposta Lexicográfica. Tese (Doutorado em Linguística) - a Instituto de Letras, Departamento de Linguística, Português e Línguas Clássicas, Universidade de Brasília. Brasília, 2009.

FERREIRA-BRITO, L. Por uma gramática de línguas de sinais. Rio de Janeiro: Tempo Brasileiro, 1995.

. Similarities and Differences in Two Sign Languages. Sign Language Studies. 42: 45-46. Silver Spring (USA): Linstok Press, 1984.

. Epistemic, Alethic, and Deontic Modalities in a Brazilian Sign Language. In: FISHER, S.D.; SIPLE, P. Theoretical Issues in Sign Language Research. Vol. 1. University of Chicago Press, 1990.

. Integração social e educação de surdos. Rio de Janeiro: Babel, 1993.

FELIPE, T. A relação sintático - semântica dos verbos e seus argumentos na LIBRAS. Tese (Doutorado em Linguística) - PósGraduação em Linguística, Universidade Federal do Rio de Janeiro. Rio de Janeiro, 1998.

JUNTA DE MISSÕES NACIONAIS DA CONVENÇÃO BATISTA BRASILEIRA. Manual de sinais bíblicos: O clamor do silêncio. Rio de Janeiro, RJ, 1991. 
LIMA, V. L. S. Língua de sinais proposta terminológica para a área de desenho arquitetônico. Tese (Doutorado em Linguística Teórica e Descritiva) - Programa de Pós-Graduação em Estudos Linguísticos, Universidade Federal de Minas Gerais. Belo Horizonte, 2014.

KARNOPP, L. B. Fonética e fonologia. Apostila do curso de Letras-Libras licenciatura e bacharelado. Florianópolis: UFSC, [s/d]. Disponível em: $<$ http://www.libras.ufsc.br/colecaoLetrasLibras/eixoFormacaoBasica/ foneticaEFonologia/assets/359/FoneticaFonologia $>$. Acesso em: 26/10/2016.

Aquisição do Parâmetro Configuração de Mão dos Sinais da LIBRAS: estudo sobre quatro crianças surdas filhas de pais surdos. Dissertação (Mestrado em Linguística e Letras) - Instituto de Letras e Artes, Pontifícia Universidade Católica do Rio Grande do Sul. Porto Alegre, 1994.

Aquisição fonológica na Língua Brasileira de Sinais: estudo longitudinal de uma criança surda. Tese (Doutorado em Linguística e Letras) - Instituto de Letras e Artes, Pontifícia Universidade Católica do Rio Grande do Sul. Porto Alegre, 1999.

KRIEGER, M. G. Terminologia em contextos integradores: funcionalidade e fundamentos. Organon, Porto Alegre, $n^{\circ}$ 26, 1998.

MARTINS, A. C. Lexicografia da Língua de Sinais Brasileira do Rio Grande do Sul. Dissertação (Mestrado em Psicologia Experimental) Instituto de Psicologia, Universidade de São Paulo, 2012.

MARINHO, M. L. O Ensino da Biologia: o intérprete e a geração de sinais. Dissertação (Mestrado em Linguística) - Programa Pós-Graduação em Linguística, Universidade de Brasília. Brasília, 2007. 
OATES, E. Linguagem das Mãos. Gráfica Editora Livro S A. Rio de Janeiro, 1969.

OLIVEIRA, J. S de. Análise descritiva da estrutura querológica de unidades terminológicas do glossário letras-libras. Tese (Doutorado) - Programa de Pós-Graduação em Estudos da Tradução, Universidade Federal de Santa Catarina. Florianópolis, 2015.

Glossário Letras-Libras como ferramenta para formação/ consulta de tradutores. In: Congresso Nacional de Pesquisas em Tradução e Interpretação de Libras e Língua Portuguesa, 2010, Florianópolis. Disponível em: <http://www.congressotils.com.br/anais/anais2010/ Janine $\% 20$ Soares $\% 20$ de $\% 20$ Oliveira.pdf>. Acesso em: 17 mar. 2016.

QUADROS, R. M. de. Phrase structure of Brazilian sign language. Tese (Doutorado em Linguística e Letras) - Instituto de Letras e Artes, Pontifícia Universidade Católica do Rio Grande do Sul. Porto Alegre, 1999.

Educação de surdos: a aquisição da linguagem. Porto Alegre: Artes Médicas, 1997.

QUADROS, R. M. de.; KARNOPP, L. B. Língua de sinais brasileira: estudos linguísticos. Porto Alegre: ArtMed, 2004.

SOUSA, F. de.; SILVEIRA, H. E. da. Terminologias Químicas em Libras: A Utilização de Sinais na Aprendizagem de Alunos Surdos. Revista Química Nova na Escola. São Paulo, Vol. 33, N 1, fev. 2011.

STUMPF, M. R. Aprendizagem de Escrita de Língua de Sinais pelo Sistema Signwriting: Línguas de Sinais no papel e no computador. Tese (Doutorado) - Universidade Federal do Rio Grande do Sul. Faculdade 
de Educação. Programa de Pós-Graduação em Informática na Educação. Porto Alegre, 2005.

STUMPF, M. R.; OLIVEIRA, J. S.; MIRANDA, R. D. Glossário Letras Libras: A trajetória dos sinálarios no curso: Como os sinais passam a existir? In: QUADROS, R. M. (Org) Letras Libras: Ontem, hoje e amanhã. Florianópolis: Ed. Da UFSC, 2014.

TESTEMUNHAS DE JEOVÁ. Linguagem dos sinais. Cesário Lange, SP: Sociedade Torre de Vigia de Bíblias e Tratados, 1992. 